\title{
The Design and Implementation of Community Service System Convenient for People
}

\author{
Shuang Zhao ${ }^{1, a^{*}}$, Guozhang Jiang ${ }^{1, b}$, Hao Zou ${ }^{1, c}$, Zhujun $\mathrm{Li}^{1, d}$, \\ Minghao Chen ${ }^{1, e}$ and Rong Chen ${ }^{1, f^{\prime}}$ \\ ${ }^{1}$ Wuhan University of Science and Technology, China \\ a1529951757@qq.com, bwhjgz@wust.edu.cn, c1052427946@qq.com, d1617753062@qq.com, \\ e1174013165@qq.com, ${ }^{\mathrm{f}} 171228487 @ q q . c o m$
}

Keyword: Intelligent community; Community convenient for people; Service system; Internet service

\begin{abstract}
Conforming to the trend of the times, the relevant provisions about city community construction was put forward to help people enjoy a happy life. The community construction has a fast development At home and abroad, and all countries start to research how to establish a mature and efficient smart community. Intelligence community construction includes many parts, and one of them is community service system convenient for people focused extensively.
\end{abstract}

\section{Introduction}

With the development of reforming in our country, the spirit material needs for people are improved obviously. In order to meet the increasing spirit material needs for people, in recent years, the new urbanization state plan (2014-2020) related terms was issued. The government have realized intelligent city as new goal in future city construction, increasing to constriction dynamics of intelligent community. [1] Due to a lack of cutting-edge technology and professional talents, government focused to construction of the pilot for intelligent community. It is important part and hot fields of intelligence community to community service system convenient for people. Government must to strengthen construction of autonomy and convenient ability during the twelfth five-year, and launching wisdom city and community, improving community management and service system to meet people's needs, speeding the construction of city information, building a platform which can assist community of self-management and providing a service for people to establish a mature and perfect intelligent community which will be a main direction during the twelfth five-year. [2] Intelligence community aims to collect information data related to residents' daily life to calculate and transfer by cloud computing, internet and information intelligent terminal. Then calculating life work of residents and predicting what questions will happen to provide an intelligent, safe and convenient living environment. It is more intelligent, safe, happy, harmonious and civilized for people [3].

\section{Research and Construction Situation of Intelligence Community both at Home and Abroad}

After the long research of relative department, intelligence community construction is still groping for testing at home and abroad and there is not having a perfect construction mode. First, solve the problem of public service with equalization, because community infrastructure is an essential part of any community. It is carefully needed to research for experts and scholars to how to construct properly this community infrastructure and how to make the convenience service continue better. In terms of government at the grass-roots level, a series of standard quality should be provided to construct it which will help self-management and service convenient for people. So the construction of information platform still main methods to establish intelligence community, and integrated multi-functional system can achieve service function which is stronger than single function of application. Therefore it is a direction of developing intelligent community service to exploit a comprehensive multi-functional system. 


\section{Brief Description the Community Service System Convenient for People}

The important point of community service is providing a convenient service for special people such as providing a high help and comprehensive service, creating a good environment for unemployed personnel. [4]Community service will become a full of potential and prospect road of developing basic services since the reform and opening.

Connotation of community service is expressed in many ways which are spontaneous, voluntary, organizing, disciplining and systemic. In addition to that, community service convenient for people is no longer common new normal of social service industry in today social ideology which has two main forms, and one is that a few people provide convenient service for majority of people. Another is community public welfare activity form which is made up of self-help and mutual aid.

Role in promoting community service system convenient for people have a good affection not only in the community construction of material civilization but also in construction of spiritual civilization. Community residents needn't keep house all days by this system and own more time to do what they want, improving residents' living quality. Besides, this system service will provide a lot of life service and social welfare to make people better and convenient. [5]Community service system convenient for people applicate to a small scale of community service resources and solve community service problem in daily life, and focusing on the needs of residents' real life to achieve free door-to-door service and improve service quality in ensuring supply and demand both sides trust each other. Thus, this system which is convenient to use for people will make the best choice in the first time by knowing residents' life and consumption habits.

\section{Comprehensive Foreign Study Characteristics}

At present, the guiding in our country is the livelihood of the people first, carrying out basic public service with equal, ensuring and improving people's livelihood and enjoying the achievement of reforming and opening. Community as the most grass-roots organizations is main battlefield to achieve basic public service. The fast development of community service is the important part to realize people's livelihood first. We can reference and study others successful experience of this system and avoiding detours to establish a system belonging to china.

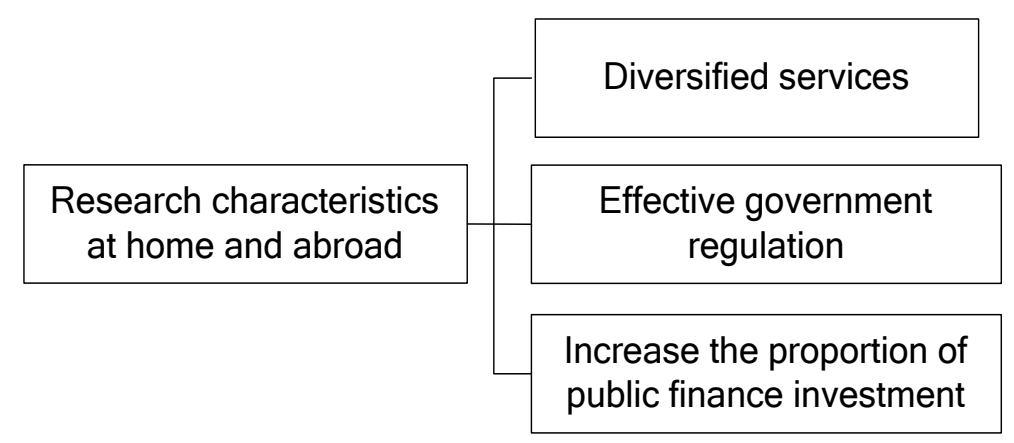

Figure 1. Research characteristics at home and abroad

Diversified Services. At present our country for the community service is still by the government as a single main body, not with enterprises and individuals to carry on the linkage. This is different from the western developed countries; they are taking a multi linkage model to build community services. All social resources are integrated, so as to accelerate the construction of community convenience services. Because of introducing the resources of all directions in the society, The government can use its own resources in the construction of social core public services and facilities. Ultimately, each resident can live more intelligent, convenient and diversified.

To Ensure Effective Regulation of the Government. The community service system of the Nordic countries have more institutionalized than in other countries. Because of the Nordic 
countries government has strict and effective supervision of community service. Under the new situation of multi linkage instead of the original single subject, the government is no longer fully control the construction and development of public services and facilities as it has in the past. The government has become a lubricant to participate in the main body to ensure that the entire system can operate normally. Therefore, it is needed to improve the government's ability to monitor and regulate the distribution of benefits among different participants.

Improve the Public Finance Investment Proportion. Comparing to financial investment in basic public services of social security, health, education and employment in the developed countries, it remains to be improved. Investment in basic public service in the Norwegian is $65 \%$ in total spending every year, $61 \%$ in this aspect in United States. So a lot of investment is put into public service, especially these activities of nonprofit nature and Welfare nature have solved money problems and seek the breakthrough in technology. It will construct and develop community public service better.

\section{Analyzing Design Principle of Community Service System Convenient for People}

In the Aspect of the Overall Framework. The construction of community service system convenient for people needs to have the aid of information processing technology of new internet of things, cloud computing, data optimization, and connecting with public service and information as well as commercial infrastructure in community and a range of areas by cognition of data, network and intelligent information, informing to an intelligent digital network and establishing an community service convenient for people platform, achieving a modernization of community management and intelligent public service. Residents will live in a safe, convenient and comfortable environment [6].

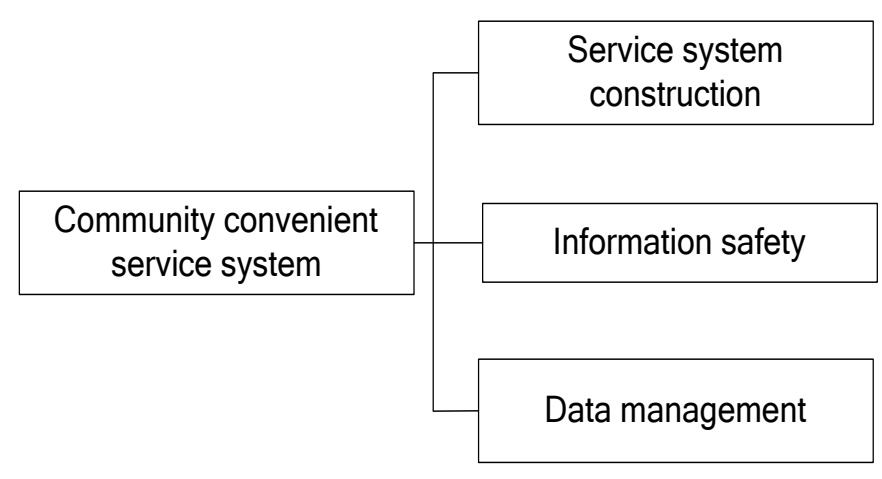

Figure 2. Community convenient service system

Community service system convenient for people should make a change in designing based on community size, guaranteeing to meet the requirements in everyday for people and reducing stress of server as far as possible to make system run efficiently and steadily. A community network will be established to ensure residents to choose colorful service content and decrease the cost of running as well as professional talented person's demand.

When community service system convenient for people is applied to every community, a unified version will is discovered. It needs certain demand for adaptability and diversity of system. So system needs many versions which is different for region of community and age section of community residents. Thus, it will meet community residents' life.

Construction in Service System. To establishing a comfortable service system to help residents realize humanized six integration systems which can service community residents. [7]Community service system convenient for people includes three main parts which are commerce consumption plate, financial information section and material circulation plate. The consumer segments including the daily life of resident's consumption, such as supermarkets, discount prices, commodity market 
community business information. Some of commercial activity will be noticed to ensure residents to buy what they want. Financial information section will release the latest news which focuses on stock market, futures and funds. Residents can learn financial information according to their own choice and make a trading activity.

Information Security Aspect. User's information security is the most important of all kinds of network data information system construction. Community service system should strengthen the security of information for community residents. For the external risks, the system has network security tools; it can be an effective defense for those from malicious network intrusion. Prevent the database from third parties to steal information, so as to better guard against information from the external security issues. In the aspect of internal information security, the system strictly controls the entry of each port. Both the client and the system server must be passed the security test to meet the safety standard before they can enter the program. At the same time, Information leakage prevention and some other security tools have set up to protect the community residents' private information and cooperation business information.

Data Management Aspect. The efficient and stable operation of the system is closely related to a good data management system. Service system as a goal to meet the needs of community residents, it requires a high demand for data management [8]. Data management needs to create a data sheet; the data list can help the system management staff to better understand the various data services system, the operation of the system. The system can be improved the work efficiency by using these data. A practical solution is proposed using centralized and distributed data integration methods [9-10].

\section{Conclusion}

Based on the research of intelligent community at home and abroad, this paper analyzes some of the common characteristics of the intelligent community. The concept and main content and other information of the community convenience service system are given. Based on the common characteristics of the domestic and foreign cases, this experience has been put forward on the establishment of community convenience service system. The preliminary design of the community service system is proposed which is based on the overall design, service system, information security and data management. With the continuous development of technology, the design of community service system will be more perfect and intelligent. Every resident can live more happiness, convenience and safety.

\section{References}

[1] X Wu, T.Y Li: Study on Planning Framework of Convenience Service System for Village and Town Communities. Journal of Urban and Regional Planning, Vol. 7(2015) No.2, p.100-111

[2] L.C Gong, P Xue: Design and implementation of digital community information management and service system. Geomatics Technology and Equipment, Vol. 10(2008) No.1, p.16-18

[3] S.S Zhu, Y.Q Zhang: Study on the design of the elderly Leisure City community social service retirement. Packaging Engineering, Vol. 36(2015) No.12, p.5-9

[4] L.M Wang, Y.Y Han and T Lei: The design of community service system. Microcomputer \& its Applications, Vol. 32(2013) No.16, p.11-13

[5] L.X Zhu Ge, N.X Liu: Key technologies of "One-Window" community affairs acceptance and process services system. Computer Systems \& Applications, Vol. 24(2015) No.1, p.74-78

[6] F.M Ma, G Wang: Method for commodity recommendation based on user community. Computer and Digital Engineering, Vol. 41(2013) No.8, p.1354-1356

[7] H F, E H: Technology, innovation and health equity. Bulletin of the Word Health Organization, Vol. 93(2015) No.7, p.438-438A 
[8] K.X Wu, X Chen and Z.Y Zhai: Design and implementation of residents 'health records management system. Computer Applications and Software, Vol. 30(2013) No.4, p.214-216

[9] X.M Wu: On construction of intelligent residential district. Shanxi Architecture, Vol. 30(2004) No.18, p.29-30

[10]L Sun: Design and application of intelligent public service broadcasting based on GIS. Video Engineering, Vol. 38(2014) No.14, p.65-68 